\title{
Microbiological and Molecular Diagnosis of Mycobacterium tuberculosis Infection in Spotted Deer (Axis axis) of an Indian Zoo
}

\author{
Sourabh Ranjan Hota ${ }^{1}$, Sarat Kumar Sahu ${ }^{2}$, Bikash Kumar Behera ${ }^{1}$, \\ Avishek Pahari ${ }^{1}$ and Niranjana Sahoo ${ }^{1}$
}

${ }^{1}$ Centre for Wildlife Health, College of Veterinary Science \& Animal Husbandry, Odisha University of Agriculture and Technology, Bhubaneswar, Odisha, India -751003

${ }^{2}$ Nandankanan Zoological Park, Bhubaneswar, Odisha, India- 754005

*Corresponding author

\section{A B S T R A C T}

\begin{tabular}{|l|}
\hline Ke y w o r d s \\
$\begin{array}{l}\text { Mycobacterium } \\
\text { tuberculosis, } 16 \mathrm{~S} \\
\text { rRNA sequencing, } \\
\text { RT PCR, Axis axis }\end{array}$ \\
\hline Article Info \\
\hline $\begin{array}{l}\text { Accepted: } \\
\text { 18 May } 2020 \\
\text { Available Online: } \\
\text { 10 June 2020 }\end{array}$ \\
\hline \hline
\end{tabular}

A detailed laboratory investigation was undertaken to correlate the cause of death in two spotted deer (Axis axis) of Nandankanan Zoological Park, Odisha, India, suspected due to Tuberculosis based on necropsy findings. The pus samples collected from lungs nodules were inoculated to Lowenstein-Jensen medium with glycerol which showed growth of buff colored smooth to bread-crump like colonies after 6-10 weeks of incubation at $37^{\circ} \mathrm{C}$. The culture positive samples were subjected to 16SrRNA PCR that amplified both the isolates producing an amplicon of 500bp size upon gel electrophoresis. Sequencing of this product yielded a gene sequence of 520 nucleotides which upon blast, showed $99 \%$ similarity with Mycobacterium tuberculosis (NCBI accession no. MH393632 and MH393637). A chip-based real-time PCR tests showing a peak Ct value of 19.5 confirmed this species. Identification of human type TB amongst spotted deer warranted implementation of effective managemental practices in the zoo.

\section{Introduction}

Tuberculosis (TB) is a widely prevalent zoonotic disease that affects both domestic and wild animal across the globe. Many zoological gardens of India viz., National Zoo, Delhi (Arora, 2000), Kanpur Zoo (Gairola, 1986), Assam State Zoo
(Chakraborty et al., 1993; Thakuria, 1996) Chhatbir Zoo, Punjab (Singh and Gupta, 1988), Nandankanan Zoological Park (NKZP), Bhubaneswar (Rao and Acharjyo, 1996) have reported tuberculosis among many species of cervids like spotted deer (Axis axis), brow-antlered deer (Rucervus eldii), hog deer (Axis porcinus), swamp deer 
(Rucervus duvaucelii), barking deer (Muntiacus muntjak), mouse deer (Moschiola indica) and antelopes like nilgai (Boselaphus tragocamelus), chinkara (Gazella bennettii), black buck (Antilope cervicapra) and four horned antelope (Tetracerus quadricornis). Human type TB caused by $M$. tuberculosis has also been isolated earlier from hog deer, black buck, spotted deer, giraffe and sambar (Upadhyay et al., 1986; Chakraborty et al., 1993; Bhowmik, 1999; Arora, 2000). Present study describes microbiological and molecular identification of $M$. tuberculosis from pus samples of lungs collected during necropsy of two spotted deer in NKZP that died in quick succession of 3 days.

\section{Materials and Methods}

\section{Sample collection}

Postmortem examination of the two spotted deer died during March 2018 revealed presence of extensive areas of caseous and abscess-like lesions in the lungs and adjoining lymph nodes with accumulated pus discharges in the pleural cavity (Figure 1).The pus samples from the pleural cavity were sampled aseptically in sterile screw-capped containers for microbiological and molecular examination.

\section{Isolation of Mycobacterium sp}

Approximately $5.0 \mathrm{ml}$ of pus sample was taken and equal volume of $4 \% \mathrm{NaOH}$ was added to it for initial decontamination (Modified Petroff's method; Vestal, 1977). The mixture was allowed to stand for 15 minutes at room temperature. Following centrifugation at $3000 \mathrm{~g}$ for 15 minutes, the supernatant was carefully removed and $15 \mathrm{ml}$ of sterile distilled water was added to resuspend the sediment. The mixture was recentrifuged at $3000 \mathrm{~g}$ for 15 minutes and a pellet was extracted after decanting off the supernatant. The processed sample was inoculated onto the slopes of LowensteinJensen slants, one with glycerol and another with sodium pyruvate, in McCartney tubes. The tubes were incubated at $37^{\circ} \mathrm{C}$ in an inclined position overnight and vertically for 8-12 weeks with weekly examination starting from three days post inoculation.

\section{Acid-fast and fluorescent staining}

Two thin smears were prepared from the colonies on L-J medium, on glass slide and stained by BD TB Ziehl-Neelsen stain kit (Becton, Dickinson and Company, Becton Drive, Franklin Lakes, NJ) and HiMedia fluorescent stain kit (HiMedia Laboratories Pvt. Limited, Mumbai, India) with Auramine $\mathrm{O}$ dye as per the manufacturer's instructions and examined under oil-immersion lens of optical microscope and fluorescent microscope, respectively for the presence of Mycobacterium.

\section{Molecular identification}

Genomic DNA was extracted from the positive culture by using DNeasy blood and tissue kit (QIAGEN GmbH - Germany) and checked for purity and quantity. The target DNA used for amplification was the first 500 bp fragment of 16SrRNA gene used for identification of unknown bacterial isolates. PCR amplification was carried out in $25 \mathrm{ml}$ reaction mixtures containing $1.0 \mathrm{ml}$ of DNA template, $20 \mathrm{pM}$ of $1.0 \mathrm{ml}$ each of forward and reverse primer, $12.5 \mathrm{ml}$ of $2 \mathrm{X}$ red dye PCR master mix (Amplicon) and $9.5 \mathrm{ml}$ of nuclease free water. The reaction mixture was subjected to initial denaturation at $94^{\circ} \mathrm{C}$ for $10 \mathrm{mins}$ followed by 30 cycles of amplification consisting of denaturation at $94^{\circ} \mathrm{C}$ for $1 \mathrm{~min}$, annealing at $54^{\circ} \mathrm{C}$ for $1 \mathrm{~min}$ and extension at $72^{\circ} \mathrm{C}$ for 1 min with a final extension at $72^{\circ} \mathrm{C}$ for $5 \mathrm{~min}$. The final PCR amplified product was separated by $1.5 \%$ 
agarose gel electrophoresis and gel documented. The primer sequence used are: 0008F (5'-AGAGTTTGATCCTGGCTCAG$\left.3^{\prime}\right)$ and 0532R (5'-TACCGCGGCTG CTGGCAC-3'). Following PCR, the product was purified from gel using QIAquick gel extraction kit (QIAGEN GmbH - Germany) and subjected to DNA sequencing.

Pus samples found positive for Mycobacterium tuberculosis were further analyzed for confirmation of species-specific pathogen using a chip-based real-time PCR test 'Truenat MTB' (Molbio Diagnostics Pvt. Ltd., Verna Industrial Estate, Verna, Goa, India).

\section{Results and Discussion}

In this study, pus samples from both the deer showed growth of buff colored smooth to bread-crump like colonies in LowensteinJensen medium with glycerol after 6 - 10 weeks of incubation at $37^{\circ} \mathrm{C}$ (Figure 2). However, no growth was observed in the L-J slants with sodium pyruvate. This shows presence of $M$. tuberculosis and absence of $M$. bovis in both the samples. Both the bacterial colonies, extracted from L-J slants, were found positive for presence of Acid Fast Bacilli (AFB) based on Z-N staining method (Figure 3). In fluorescent dye (auramine) stained slides, distinct fluorescent bacilli were observed under high power magnification of fluorescent microscope that confirmed presence of Mycobacterial AFB (Figure 4).

Sequencing of 16SrRNA PCR amplified products yielded a gene sequence of 520 nucleotides (Figure 5) which upon blast, showed 99\% similarity with Mycobacterium tuberculosis. The said gene sequences has been submitted in the NCBI gene bank with accession no. MH393632 and MH393637. Further analysis of pus samples in Truenat (chip-based) real-time PCR test revealed presence of Mycobacterium tuberculosis that produced a peak at $\mathrm{Ct}$ value of 19.5 (Figure 6 ). It double checked the findings of sequence results.

Figure.1 Cut surface of lungs showing extensive areas of caseous and abscess-like lesions

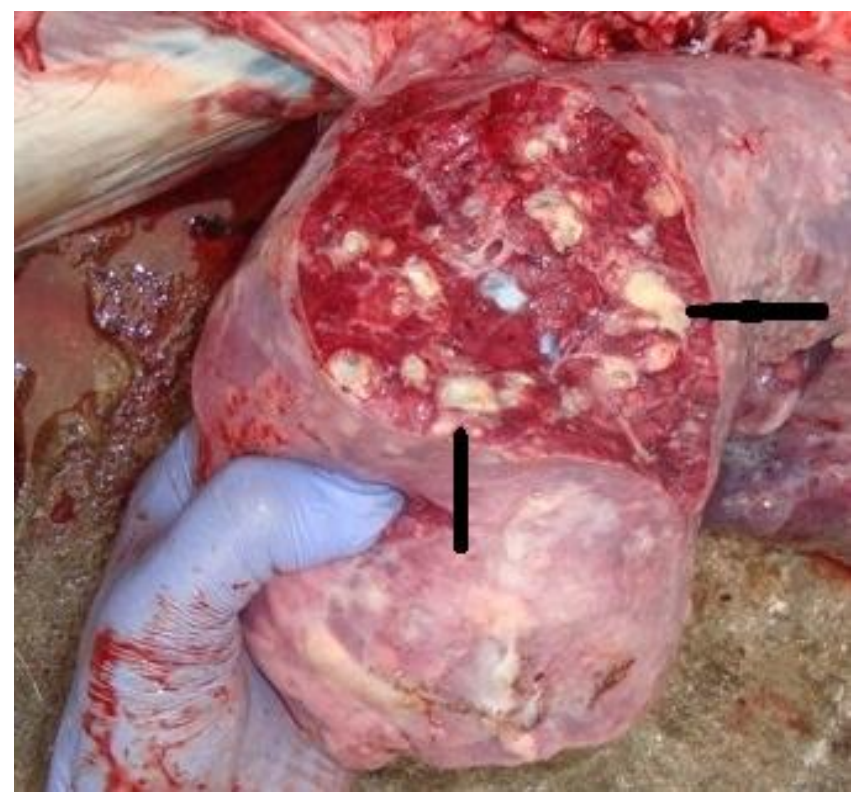


Figure.2 Buff colored bread-crump like colonies in Lowenstein-Jensen medium with glycerol after 6 - 10 weeks of incubation at $37^{\circ} \mathrm{C}$

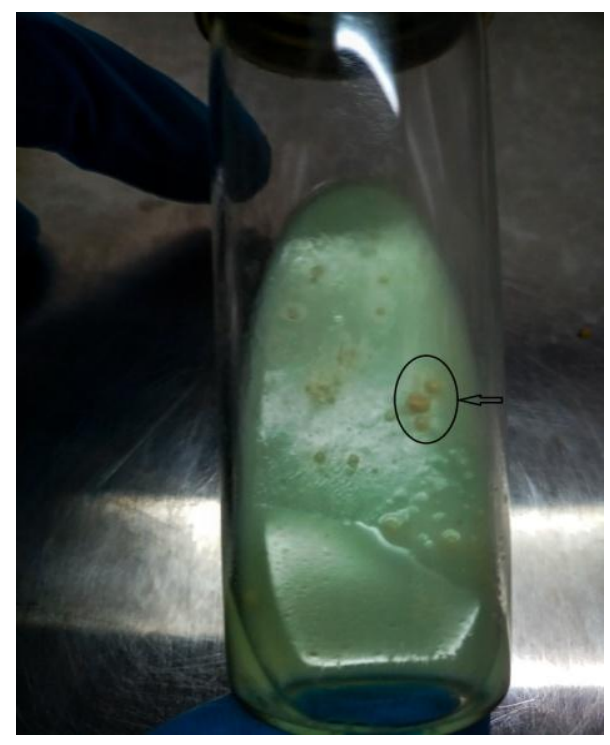

Figure.3 Acid Fast Bacilli (AFB) based on Z-N staining under oil immersion lens (100x)

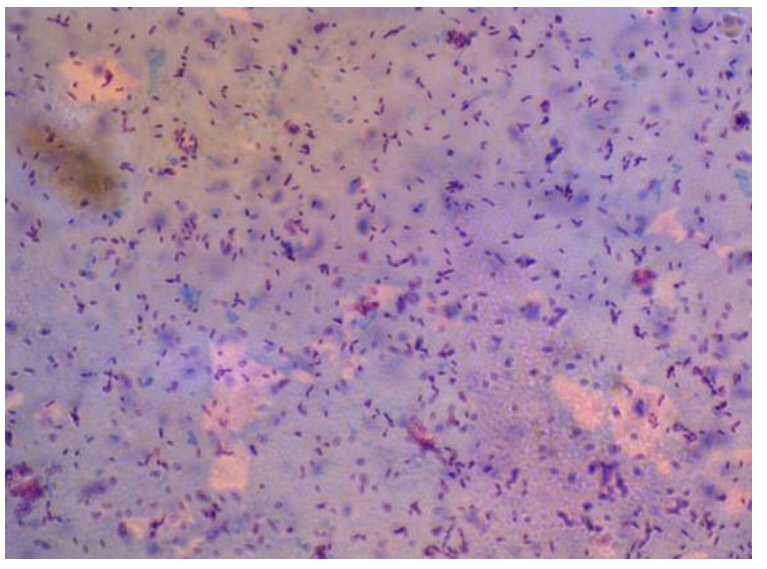

Figure.4 Fluorescent bacilli under high power magnification (100x)

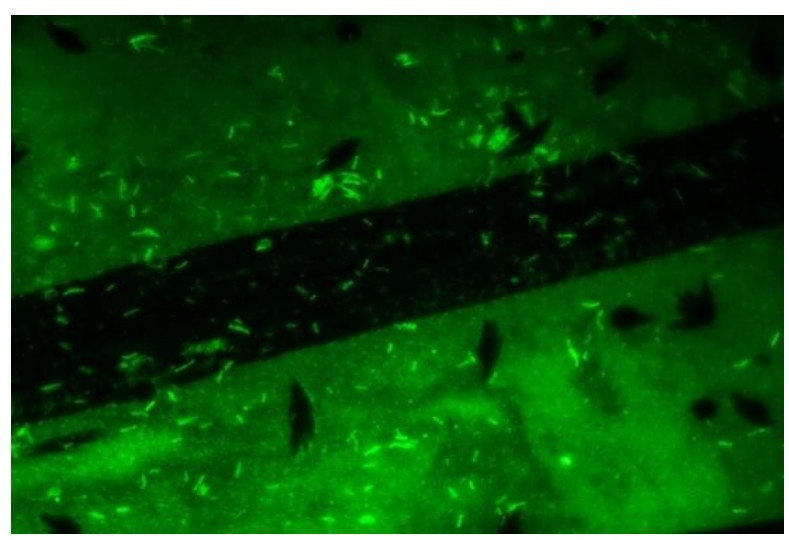


Figure.5 PCR showing 500bp fragment of 16SrRNA of the bacterial isolate. Lane 1-1000bp gene marker, Lane 2- Negative control, Lane 3- Test sample and Lane 4 - Positive control

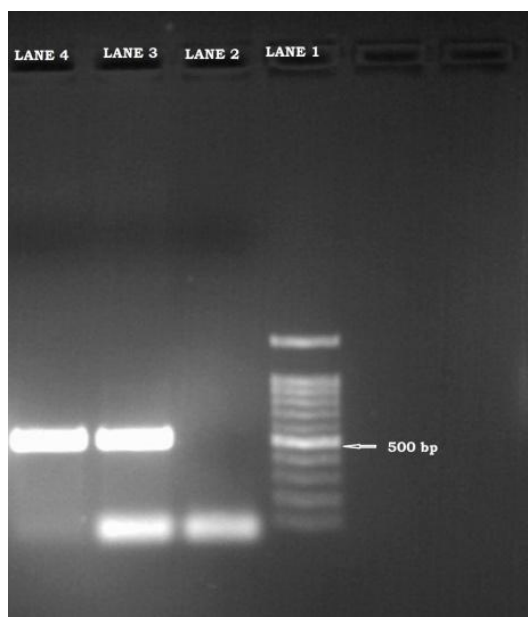

Figure.6 Truenat (chip-based) real-time PCR test revealed presence of Mycobacterium tuberculosis that produced a peak at $\mathrm{Ct}$ value of 19.5

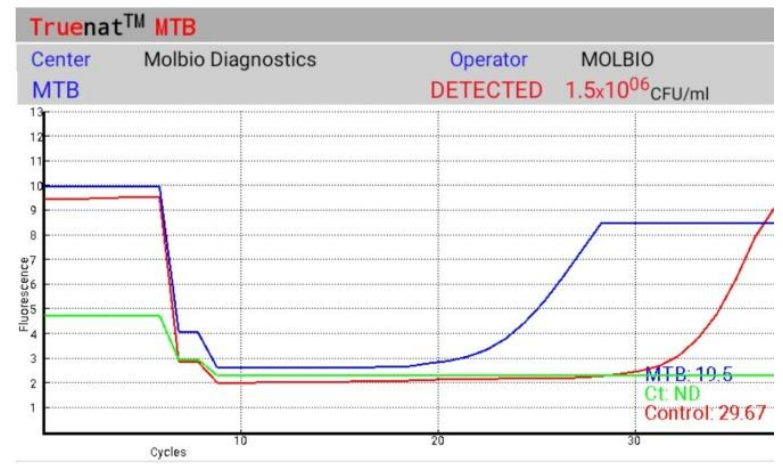

Bovine TB predominantly caused by $M$. bovis and seldom $M$. tuberculosis, continues to be a matter of concern for its potential zoonotic risks. South Asia consisting of eight countries, namely, Afghanistan, Bangladesh, Bhutan, Maldives, Nepal, Pakistan, Sri Lanka, and India has emerged as a focal spot for tuberculosis witnessing one of the highest incidence rates sharing more than one-third (34\%) of the world's human TB burden (Thapa et al., 2017). In the similar scale tuberculosis is of paramount importance in captive wildlife across zoological collections globally (Montali et al., 2001). Isolation and identification of Mycobacterium tuberculosis from both the spotted deer at NKZP, runs against the common notion of $M$. bovis as the common cause of TB associated mortality in herbivores including deer (Kaneene et al., 2010).

Severe outbreaks of tuberculosis in deer are uncommon though in captive settings a large number of animals are likely to be infected sub-clinically (Waters et al., 2011). In deer, tuberculosis is a sub-acute to chronic disease and even the critically infected ones may not demonstrate obvious clinical signs before death (Palmer et al., 2015). Absence of clinical signs in both the spotted deer in our study supports this statement. This may be the result of one or more animals acting as 
'shedders', efficiently transmitting disease to herd mates.

NKZP harbors more than 1200 no. of cervids with spotted deer acquiring the major share of the pie. Therefore, detection of TB in this species significantly elevates the possibility of the existence of this infection in neighboring susceptible hosts. There is a common perception that TB can spread uncontrollably in captive deer herds (Essey and Koller, 1994). This message was reinforced by Parra et al., (2005), who observed that the deer involved in a TB outbreak, possibly can maintain the transmission cycles over long periods of time, lasting at least up to 3 years in the same area.

Presence of $M$. tuberculosis and absence of $M$. bovis in both the positive samples in our findings raised the possibility of human-toanimal transmission and possible adaptation of this organism in animal tissues. As per Thoen and Steele (1995), humans suffering from active TB are the most probable source of $M$. tuberculosis infection for animals. A number of researchers have reported the existence of $M$. tuberculosis in domestic and wild animals, most frequently living in close contact with humans (Montali et al., 2001; Sternberg et al., 2002; Alfonso et al., 2004). Most reports of $M$. tuberculosis infection in animals are confined to developing countries with a high prevalence of human TB (Epstein and Price, 2009). Hutchings and Harris (1997) stressed that inhalation of bacilli from grass contaminated with infected human urine, faeces, or sputum may be the most important route of transmission of $\mathrm{TB}$ from human to animals. Poor hygiene, overcrowding, unsuitable environments and close contact to visitors may also act as an aggravating factor in transmission of TB (Kohn, 1994). It is not unwise to speculate that this shift is likely to lead to a net increase in the incidence of $M$. tuberculosis in captive animal populations of
Zoological Parks with parallel increase in visitors' entry.

Exposure and infection of captive wildlife in a high TB prevalent country like India, is therefore a growing concern not only for wildlife bio-diversity conservation but also for human health. This further escalates the concern of public health hazard of retrograde transmission of TB from wild animals to humans through potential spillback. In this context, Barron et al., (2013) described the emerging role of deer in TB epidemiology as a persistent source of infection to humans. In addition to a string of reports available on wild deer acting as a reservoir of infection, Palmer et al., (2012) reported 'spilling back' of infection from wild to domestic animals. Chu et al., (2012) demonstrated that deer may be the reservoir for $M$. tuberculosis, posing as a potential public health threat.

Present finding would be helpful at formulating a strategic approach towards prevention of TB not only for captive wild animals of the zoo but also for the human resources that work in close contact with these animals.

It can be concluded that the death in two spotted deer in quick succession of three days and the confirmation of $M$. tuberculosis infection through molecular diagnosis, raises concern regarding the possibility of existence of infection among other deer species in the neighbouring herbivore enclosures. The zoonotic potential of the pathogen warranted immediate implementation of a comprehensive preventive protocol that would combat the disease in the zoo.

\section{Acknowledgement}

The authors express their deep sense of thanks and gratitude to the Director, Nandankanan Biological Park, Forest and Environment 
Department, Government of Odisha, for his kind support during the entire period of study.

\section{References}

Alfonso, R., Romero, R.E., Diaz, A., Calderon, M.N., Urdaneta, G., Arce, J., Patarroyo, M.E., Patarroyo, M.A. 2004. Isolation and identification of mycobacteria in New World primates maintained in captivity. Veterinary Microbiology, 98: 285-295.

Arora, B. M. 2000. Tuberculosis- an impediment to wildlife conservation. Souvenir- 125 (1875-2000) years of Calcutta zoo. pp. 81-91

Barron, M.C., Nugent, G., Cross, M.L. 2013. Importance and mitigation of the risk of spillback transmission of Mycobacterium bovis infection for eradication of bovine tuberculosis from wildlife in New Zealand. Epidemiology and Infection, 141: 1394-1406.

Bhowmik, M. K. 1999. Disease spectrum and fawn mortality of hog deer (Axis porcinus) in Eastern Himalayan region. National Symposium on topics of current interest in Pathology of animal and poultry diseases. The Millennium Approach. 25-27 November 1999, Bangalore pp 131-136

Chakraborty, A. Sarma D. K., Choudhury, B. 1993. Tuberculosis in captive herbivores. Indian Journal of Veterinary Pathology, 17: 58-60

Chu, C., Yu, C., Chen, C., Su, Y. 2012.Mycobacterium tuberculosis and M. bovis infection in Feedlot Deer (Cervus unicolor swinhoei and $C$. nippontaiouanus) in Taiwan. Journal of Microbiology, Immunology and Infection, 45: 426-434.

Epstein, J. H. and Price, J. T. 2009. The significant but understudied impact of pathogen transmission from humans to animals. Mount Sinai Journal of
Medicine, 76: 448-455.

Essey, M.A. and Koller, M.A. 1994. Status of bovine tuberculosis in North America. Veterinary Microbiology, 40: 15-22.

Gairola, H. K. 1986. Zoo mortalities- causes and control. Zoo's Print. 1:8-11

Hutchings, M.R. and Harris, S. 1997. Effects of farm management practices on cattle grazing behaviour and the potential for transmission of bovine tuberculosis from badgers to cattle. The Veterinary Journal, 153: 142-162.

Kaneene, J.B., Miller, R., I. N. de Kantor, Thoen, C. O. 2010. Tuberculosis in wild animals. International Journal of Tuberculosis and Lung Disease, 14(12): 1508-1512.

Kohn, B.1994. Zoo animal welfare. Revue Scientifique et Technique 3: 233-245.

Montali, R.J., Mikota, S.K., Cheng, L.I. 2001. Mycobacterium tuberculosis in zoo and wildlife species. Scientific and Technical Review, 20: 291-303.

Palmer, M.V., O'Brien, D.J., Griffin, J.F., Nugent, G., Lisle, G.W., Ward, A., Delahay, R.J. 2015. Tuberculosis in Wild and Captive Deer. Tuberculosis, Leprosy and Mycobacterial Diseases of Man and Animals: The Many Hosts of Mycobacteria, 334-364.

Palmer, M.V., Thacker, T.C., Waters, W.R., Gortazar, C., Corner, L.A. 2012. Mycobacterium bovis: a model pathogen at the interface of livestock, wildlife, and humans. Veterinary Medicine International. doi: $10.1155 / 2012 / 236205$.

Parra, A., Larrasa, J., Garci'a, A., Alonso, J.M., Hermoso de Mendoza, J. 2005. Molecular epidemiology of bovine tuberculosis in wild animals in Spain: A first approach to risk factor analysis. Veterinary Microbiology, 110: 293-300.

Rao, A. T and Acharjyo, L. N. 1996. Tuberculosis in Nandankanan Biological Park- An overview: The Blue 
Cross Book, 7: 31-35.

Singh, B. and Gupta, P. P. 1988. Causes of mortality in zoo animals. Proc- $1^{\text {st }} \mathrm{All}$ India Zoo Veterinarian Seminar, Chandigarh. 02-03 December, 1988. pp 54-58.

Sternberg, S., Bernodt, K., Holmstrom, A., Roken, B. 2002. Survey of tuberculin testing in Swedish zoos. J Zoo Wild Med, 33(4): 378-380.

Thakuria, D. 1996. Prevalence, transmission, diagnosis and control of tuberculosis in Assam State Zoo: A overview, Zoo's Print, 11: 6-15

Thapa, J., Nakajima, C., Gairhe, K.P., Maharjan, B., Paudel, S., Shah, Y., Mikota, S.K., Kaufman, G.E., McCauley, D., Tsubota, T., Gordon, S.V., Suzuki, Y. 2017. Wildlife Tuberculosis: An Emerging Threat for Conservation in South Asia. In: Global Exposition of Wildlife Management, Lameed G.A. ed. In Tech. pp. 73-90.

Thoen, C.O. and Steele, J.H. 1995. Mycobacterium bovis infection in animals and humans. Iowa State University Press, Iowa, USA.
Upadhyay, T. N., Rahman, T., Pathak, D. C., Baruah, D. K., Baruah, G. K. 1986. Tuberculosis in captive deer. Indian Veterinary Journal, 63: 865-866.

Vestal, A.L. 1977. Procedures for the isolation and identification of mycobacteria. Dept. of Health, Education, and Welfare, Public Health Service, Center for Disease Control, Bureau of Laboratories, Training and Consultation Division.

Waters, W.R., Stevens, G.E., Schoenbaum, M.A., Orloski, K.A., Robbe-Austerman, S., Harris, N.B., Hall, S.M., Thomsen, B.V., Wilson, A.J., Brannian, R.E., Nelson, J.T., Schafer, S., Esfandiari, J., Dutton, M., Greenwald, R., Lyashchenko, K.P. 2011. Bovine tuberculosis in a Nebraska herd of farmed elk and fallow deer: a failure of the tuberculin skin test and opportunities for sero diagnosis. Veterinary Medicine International,95: 39-85.

\section{How to cite this article:}

Sourabh Ranjan Hota, Sarat Kumar Sahu, Bikash Kumar Behera, Avishek Pahari and Niranjana Sahoo. 2020. Microbiological and Molecular Diagnosis of Mycobacterium tuberculosis Infection in Spotted Deer (Axis axis) of an Indian Zoo. Int.J.Curr.Microbiol.App.Sci. 9(06): 844-851. doi: https://doi.org/10.20546/ijcmas.2020.906.107 